\title{
POSTINFARCTION VENTRICULAR SEPTAL RUPTURE: EARLY REPAIR THROUGH THE RIGHT ATRIAL APPROACH
}

Massimo Massetti, MD

Gerard Babatasi, MD, $\mathrm{PhD}$

Olivier Le Page, MD

Satar Bhoyroo, MD

Eric Saloux, MD

Andre Khayat, MD
Objective: Early repair of posterior ventricular septal rupture associated with myocardial infarction by means of transinfarct ventriculotomy is technically challenging and can be associated with significant mortality and morbidity. An alternative route of exposing the septum is through the right atrium. This technique, which avoids direct incision of the ventricle in select patients, reduces postrepair bleeding and impairment of ventricular contractile function.

Methods: The results of 12 patients operated on over a 20 -year period were reviewed and analyzed. Late follow-up was obtained in all patients who survived the operation. There were 9 men and 3 women, with a mean age of 69.9 years. The mean time between acute myocardial infarction and surgery was 7.3 days (range, 2-16 days). Six patients were in New York Heart Association class IV, and 3 patients presented for surgery in cardiogenic shock. One patient had previously undergone a coronary artery bypass. The surgical technique included a standard sternotomy approach with a transatrial approach to the septal rupture. In all patients the septal rupture was repaired with a Dacron patch.

Results: There were 3 early deaths and 1 late death; one patient was reoperated on for a residual shunt. Postoperative complications included low cardiac output, acute renal tubular necrosis, and supraventricular arrhythmia. Eight patients are alive and undergoing echocardiographic investigation, and only 1 patient had a small residual shunt.

Conclusion: Our experience shows that a posterior ventricular septal rupture can be safely repaired through a transatrial approach. Avoiding additional damage to the ventricle, it reduces the risks of the postoperative bleeding and enhances survival. (J Thorac Cardiovasc Surg 2000;119:784-9)
$A^{\mathrm{n}}$ pproximately $1 \%$ of cases of acute myocardial infarction are complicated by ventricular septal rupture (VSR). ${ }^{1-3}$ This mechanical complication usually occurs within the first 10 to 14 days when necrotic tissue is most abundant and the collateral coronary circulation is not well developed. ${ }^{4}$ Generally associated with complete coronary obstruction rather than severe stenosis, this lesion is associated with an $87 \%$ mortality with-

From the Thoracic and Cardiovascular Surgery Department, University Hospital, Caen, France.

Received for publication July 27, 1999; revisions requested Sept 20, 1999; revisions received Nov 8, 1999; accepted for publication Nov 17, 1999.

Address for reprints: Massimo Massetti, MD, Thoracic and Cardiovascular Surgery Department, University Hospital, 14033 Caen, France (E-mail: massetti-m@chu-caen.fr).

Copyright (C) 2000 by The American Association for Thoracic Surgery.

$0022-5223 / 2000 \$ 12.00+0 \quad \mathbf{1 2 / 1 / 1 0 4 4 6 7}$

doi:10.1067/mtc. 2000.104467 in 2 months if treated medically. ${ }^{5}$ Therefore postinfarction ventricular septal rupture (VSR) is almost always lethal unless surgically corrected, and these patients should be operated on during the acute phase of the myocardial infarction before cardiogenic shock and its complications ensue. The presentation of septal rupture complicating anterior myocardial infarctions is somewhat more frequent than that associated with an inferior location of myocardial infarction, and the operative mortality rate is higher with surgical repair. Also, the preoperative presence of cardiogenic shock is more common than that found in an inferior myocardial infarct. 2,3,5,6-11 Surgical repair of a VSR was first achieved successfully by Cooley and associates ${ }^{12}$ in 1956; since then, numerous cardiac surgeons have contributed to the development of surgical principles leading to successful early closure of VSR. It has been suggested that early surgical outcome is determined by the time interval between infarction and operation, the surgical technique used, and the degree of ventricular impairment. Operative 
techniques included infarctectomy and reconstruction of the ventricular septum and free walls of the heart with Dacron patches $3,6,7,13$; others emphasize infarct exclusion of the left ventricle by an endocardial patch, leaving the right ventricle undisturbed. ${ }^{14}$ The classic surgical opening to the septum has been a ventriculotomy through the infarcted area. Rarely, surgeons approached this lesion through the right atrium ${ }^{15-22}$ because of poor exposure and the technical difficulties of repairing the friable septum. This article reports the results of a selected group of 12 patients in whom a postinfarction VSR was operated on early by means of a transatrial approach. A retrospective analysis was performed on the hospital chart. Follow-up data were complete for all the patients. Technical problems and the long-term results are discussed.

\section{Patients and methods}

Patients. The records of 12 patients who underwent surgical repair of a postinfarction VSR between January 1978 and December 1998 were reviewed. Patient data were identified from the Cardiac Unit Surgical Database, and the current status of the survivors at last follow-up was ascertained by telephone interview with the patient and by checking with the cardiologist or general practitioner. Preoperative patient characteristics and risk factors are given in Table I. One patient had received thrombolytic therapy with streptokinase within 12 hours of the onset of chest pain. One patient had previously (7 years earlier) undergone a coronary artery bypass procedure for triple vessel disease; 2 of the 3 bypass grafts were occluded. Three patients presented for surgical therapy with frank cardiogenic shock or low cardiac output syndrome (hypotension, oliguria, decreased mentation, metabolic acidosis, and the need for continuous inotropic infusions). Two of these patients had undergone successful resuscitation from ventricular fibrillation, and one exhibited third-degree heart block at the time of surgery.

Four patients had evidence of congestive heart failure (tachycardia, pulmonary congestion, fluid retention, tachypnea, and dyspnea) preoperatively in the absence of shock or low cardiac output syndrome.

Surgical technique. The heart is approached through a classic median sternotomy. Total cardiopulmonary bypass is established by cannulation of the ascending aorta and direct bicaval cannulation. Moderate systemic hypothermia $\left(32^{\circ} \mathrm{C}\right)$ was used, and after the aorta was clamped, a left ventricular vent was placed through the right superior pulmonary vein. Myocardial protection was achieved by means of cold crystalloid cardioplegic solution delivered in an antegrade manner through the ascending aorta or in a retrograde manner through the coronary sinus. The initial volume depended on the patient's body mass, and successive doses were injected according to myocardial temperature (monitoring probe). The right atrium was obliquely opened at the level of the crista terminalis. Stay sutures were used to improve exposure. The tricuspid valve leaflets and their chordae tendineae were retract-
Table I. Preoperative clinical profile and risk factors of patients with postinfarction VSR

\begin{tabular}{ll}
\hline Age at operation (y) & \\
Mean & 69.9 \\
Range & $56-78$ \\
Sex & \\
Male & $9(75 \%)$ \\
Female & $3(25 \%)$ \\
Diabetes & $3(25 \%)$ \\
Hypertension & $7(58.3 \%)$ \\
Prior evidence of CAD & \\
Angina & $6(50 \%)$ \\
CHF & $2(16.6 \%)$ \\
Both & $4(33.3 \%)$ \\
Extent of CAD & \\
Single-vessel & $6(50 \%)$ \\
Double-vessel & $5(41.6 \%)$ \\
Triple-vessel & $1(8.3 \%)$ \\
Preoperative cardiogenic shock & $3(25 \%)$ \\
Preoperative IABP insertion & $4(33.3 \%)$ \\
Preoperative fibrinolysis & $1(8.3 \%)$ \\
Site of acute myocardial infarction & \\
Inferior & $12(100 \%)$ \\
Extension to the right ventricle & $12(100 \%)$ \\
Site of VSD & \\
Inferobasal & $12(100 \%)$ \\
Time intervals (d), mean (range) & \\
MI-VSD & $7.3(2-16)$ \\
\hline$C A D$, Coronary artery disease; $C H F$, congestive heart failure; $I A B P$, intra-aortic \\
balloon pump; $V S D$, ventricular septal defect; $M I$, myocardial infarction. \\
\end{tabular}

ed; the location of the ventricular septal defect was identified amid the right ventricular trabeculation. The edges of the septal rupture were well identified by the injection of saline solution through the left ventricular vent. When possible, the demarcation line between infarcted and healthy myocardium was identified. No infarctectomy was performed, and debridement of necrotic tissues was limited to trimming the border of the disruption. In most cases the VSR was found to be in the proximal half of the posterior septum, and to improve exposure of the basal septum, the septal leaflet had to be temporarily detached from the anulus.

A piece of Dacron patch was tailored to widely cover the hole; bovine pericardium was attached to the left ventricular side of the Dacron patch with monofilament interrupted sutures to make it impermeable. The patch was tailored to a triangular shape of approximately $4 \times 6 \mathrm{~cm}$ in most patients. The medial margin of the patch was attached to the septal defect with interrupted, pledget-supported, 3-0 polypropylene mattress suture (Davis \& Geck, Wainen, NJ). All the sutures were placed, with wide bites into viable myocardium, in such a manner as to position the large pledgets of Teflon felt onto the right ventricular side of the septum, as far away from the rim of the ventricular septal defect as possible. The base of the triangular patch was sutured to the fibrous anulus of the tricuspid valve with 4-0 continuous or interrupted polypropylene sutures. The lateral side of the patch was sutured to the posterior wall of the right ventricle, and because the tissue was usually infarcted, it was necessary to 

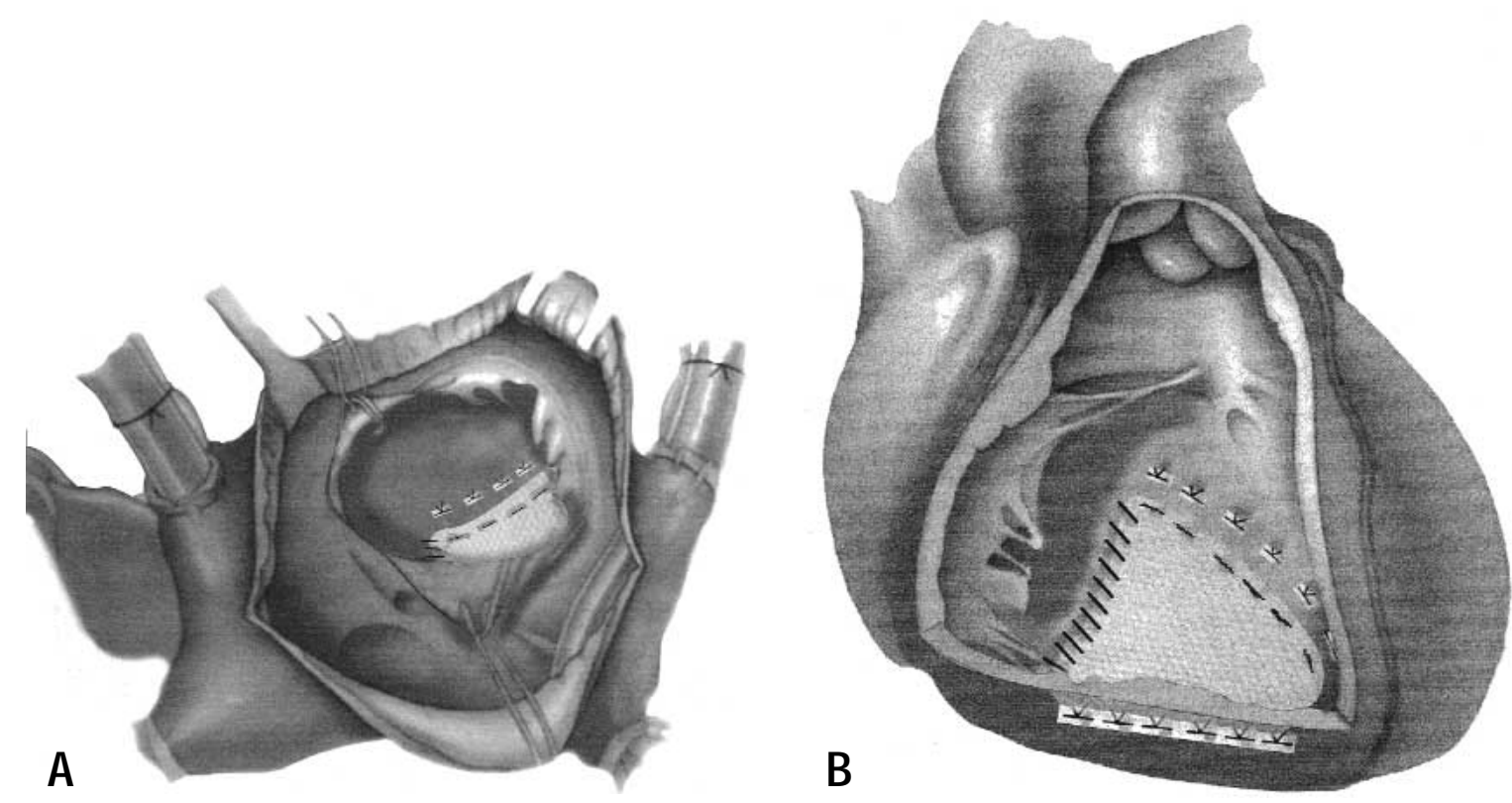

Fig 1. The repaired postinfarction ventricular septal rupture as seen through the right atriotomy (A) and the Dacron patch sutured to the right side of the septum (B).

use full-thickness bites and anchor the sutures on a strip of Teflon felt applied on the epicardial surface of the posterior free wall of the right ventricle (Fig 1). The septal leaflet was reattached to the fibrous anulus, taking every precaution to prevent injury to the conduction tissue and suturing with superficial bites as far as possible from this sensitive area. In this way the septum was stabilized, and both infarcted ventricles were left undisturbed. After completion of the repair, tricuspid competency was verified.

The integrity of the repair was tested by injecting saline solution into the left atrium and left ventricle. The operation was completed by repairing the right atrial wall. The mean aortic crossclamp time was $70 \pm 23$ minutes (range, 37 to 117 minutes), and the mean cardiopulmonary bypass time was $139.7 \pm 29$ minutes (range, 70 to 367 minutes).

\section{Results}

There were 3 early $(<30$-day) deaths. One patient could not be weaned from cardiopulmonary bypass and died in the operating room. Two patients died on the 7th and 12th postoperative days: the first as consequence of severe biventricular failure, and the second of sepsis and pneumonia. One patient was reoperated on with success for a residual shunt 3 months after the first operation. The chest tube drainage during the first 24 hours averaged $290 \mathrm{~mL} / \mathrm{m}^{2}$ (range, 220 to 1370 $\mathrm{mL} / \mathrm{m}^{2}$ ). A profuse hemorrhage related to a free-wall rupture of the right ventricle occurred in one patient 7 days after the operation. This complication was successfully repaired by using cardiopulmonary bypass and with a Teflon-supported linear suture. Postoperative complications were common: 10 patients required therapy with inotropic agents because of a low cardiac output, and 6 patients needed intra-aortic balloon pump support. Four patients required renal dialysis because of acute tubular necrosis, and all patients required prolonged ( $>48$ hours) mechanically assisted ventilation. Other complications included respiratory insufficiency $(n=5)$, septicemia $(n=3)$, supraventricular arrhythmias $(n=5)$, and a temporary third-degree heart block in 1 patient without the need for a pacemaker implantation. We observed 1 late death at 41 months postoperatively of an unknown cause. Patients were followed up for between 6 and 240 months, with a mean and SD of $59.5 \pm 28$ months. No patient was lost to follow-up. Eight patients are alive in New York Heart Association functional class I (3 patients), class II (4 patients), and class III (1 patient). On echocardiographic investigation, only 1 patient showed a small residual shunt $(<1.5: 1)$.

\section{Discussion}

Rupture of the ventricular septum is a severe mechanical complication of acute myocardial infarction, usually resulting in death unless surgical repair is performed. The bad prognosis of this event within the first 2 weeks indicates the need for early surgical repair. ${ }^{1-3,7-10,13,14,23,24}$ This complication is more frequent after the patient's first acute myocardial infarc- 
tion in the elderly and secondary to a transmural myocardial infarction. ${ }^{3}$

The outcome of patients with a postinfarction VSR is dismal, with approximately $15 \%$ surviving for 2 months and only $7 \%$ at 1 year. Several studies have found the following factors to be important in postinfarction VSR: first infarction, inferior location and transmural infarction, complete and sudden occlusion of a coronary artery, limited collateral blood flow, alteration of septal geometry, infarct extension, and left ventricular hypertrophy. ${ }^{2,3}$ The importance of right ventricular infarction on the subsequent outcome has also been demonstrated by Cummings and colleagues. ${ }^{25} \mathrm{In}$ autopsy series right ventricular infarction associated with left ventricular infarction has been found to be between $14 \%$ and $43 \%$ in the case of posterior VSD, and the outcome of patients with a posterior postinfarction VSR is largely related to the size of right ventricular infarct. ${ }^{2}$ Even within autopsy series, ischemic damage to the right ventricle is more frequent than suspected. Clinically, right ventricular dysfunction has been noted to occur in up to $40 \%$ of patients with acute infarctions, and in $100 \%$ in patients having an inferior infarction. ${ }^{25}$

The surgical mortality rate for early operation for infarction remains unchanged for the past 20 years and exceeds 30\%. 5, $711,23,24,26$ Mortality is highest for those in cardiogenic shock, with an inferiorly located VSR, and after right coronary occlusion. This higher operative mortality rate in early repair may be related more to the limited myocardial reserve and multiorgan failure associated with poor systemic perfusion than to the actual technical performance of the operation. Late repair (>1 or 2 months) is associated with significantly fewer operative deaths. However, only $15 \%$ of patients will survive to undergo surgery if such an approach is taken routinely. The debate concerning the medical versus surgical treatment of postinfarction VSR has been resolved because only those with early surgical treatment have an overall acceptable survival. Preoperative use of an intra-aortic balloon pump has been used more frequently to stabilize the patient during diagnostic studies or in preparation for surgery. ${ }^{8-11,14}$ The technical difficulties associated with early repair of the defect in necrotic friable myocardium may be related more to the interval after the acute infarction than to the interval after the actual septal rupture. The use of thrombolytic agents may shorten the interval between infarction and septal rupture.

Most surgeons advocate repairing the defect through a left ventriculotomy or through the infarcted free wall where possible. , $6,14,15,23,27$ Others suggest that repair of a VSR caused by an inferior acute myocardial infarction
Table II. Summary of 11 cases of postinfarction VSR repaired through the transatrial approach: A literature review

\begin{tabular}{lccll}
\hline First author & $\begin{array}{c}\text { Year of } \\
\text { publication }\end{array}$ & $\begin{array}{c}\text { No. of } \\
\text { patients }\end{array}$ & $\begin{array}{c}\text { Time to } \\
\text { surgery }\end{array}$ & \multicolumn{1}{c}{ Outcome } \\
\hline Filgueira $^{16}$ & 1986 & 1 & $1 \mathrm{y}$ & Alive \\
Rousou $^{21}$ & 1987 & 1 & $6 \mathrm{~d}$ & Alive \\
Calderon $^{29}$ & 1991 & 3 & Unknown & 2 alive, 1 dead \\
Pezzella $^{18}$ & 1992 & 1 & $15 \mathrm{~d}$ & Alive (res. \\
& & & & shunt) \\
Koh $^{30}$ & 1992 & 1 & $43 \mathrm{~d}$ & Alive \\
Chan $^{19}$ & 1996 & 3 & Unknown & Unknown \\
Berrizbeitia $^{15}$ & 1996 & 1 & Unknown & Unknown \\
\hline
\end{tabular}

may be performed successfully through a right ventriculotomy with the theoretic advantage of less left ventricular compromise. How aggressive the debridement of necrotic tissue should be in the ventricular septum and ventricular free wall is uncertain. Some surgeons propose using fibrin sealant or gelatinresorcin-formol glue to reinforce the necrotic interventricular septum and ventricular wall, creating a more solid implantation site for the closure of the ruptured area with a patch. ${ }^{28}$ Unfortunately, the incidence of residual or recurrent ventricular septal defect remains in the range of $15 \%$ to $20 \%$. An interesting surgical approach proposed by Cooley ${ }^{27}$ and David and colleagues ${ }^{14}$ consists of excluding rather than excising the infarcted septum and ventricular walls. This is accomplished by undertaking a left ventriculotomy through the infarcted muscle and securing a patch to the endocardium of the left ventricle all around the infarcted myocardium. The ventriculotomy is simply closed over the pericardial patch.

The transatrial approach of postinfarction VSR has not gained in popularity because of potential problems with this technique. The trabeculation of the right ventricle could make the exact identification and exposure of the VSR difficult. The placement of the patch on the right side of the septum is considered not to be optimal because of the left-to-right pressure gradient, and finally, the placement of sutures from the right side through the tricuspid valve may interfere with the chordae of the tricuspid valve and produce regurgitation. However, if these difficulties can be overcome, the transatrial approach to a posterior postinfarction VSR offers the potential for a lesscomplicated operation. Nevertheless, several points must be emphasized to perform the operation safely: the surgical exposition must be optimal. The right atrium is opened widely, and multiple stay sutures 
are used to provide exposure. The septal leaflet of the tricuspid valve may need to be divided. Identification and delineation of the VSR are achieved by injecting saline solution through a left ventricular vent placed through the right superior pulmonary vein. Placement of the patch is a difficult and demanding maneuver. Interrupted horizontal mattress sutures are placed in such a manner as to position the large pledgets of Teflon felt on the right ventricular side of the septum as far away from the rim of the rupture in the healthy myocardium. A 3-0 monofilament suture is preferred. A large thin needle is chosen to avoid further trauma to the friable septum. Interference with the tricuspid valve is avoided by placing sutures carefully between the chordae, rather than straddling them. If necessary, a tricuspid annuloplasty must be performed to eliminate any resulting tricuspid insufficiency caused by entrapment of chordae. The basal side of the patch is attached through a Teflon strip to the outside of the ventricular wall lateral to the coronary vessels. The infarcted area is excluded without excision of infarcted tissue. A stable septum is regained through the fixation of the septal patch to the right ventricular free wall. This septal stabilization without ventriculotomy prevents further deterioration of right ventricular dysfunction.

The purpose of the present report is to show an alternative operative technique for the treatment of an acquired posterior septal defect. A review of the literature showed only rare reports (Table II). Filgueira and colleagues ${ }^{16}$ in 1986 first described the use of a transatrial approach for a delayed postinfarction VSR. Rousou and colleagues, ${ }^{21} 1$ year later, successfully treated a patient 6 days after a posterior myocardial infarction. Since then, only 5 reports with this unusual approach in 9 patients have appeared. Our experience involves 12 patients operated on since 1979. In our mind the best indication for the use of this approach is when there is a large myocardial infarction in which a transventricular approach may lead to increased operative complications (eg, bleeding or low cardiac output). The other situation is when the infarct is primarily of the septum without aneurysm formation of the ventricular wall.

In conclusion, the right atrial approach to the VSR is an alternative technique of septal repair especially attractive when no obvious free ventricular wall abnormality is noted. Although tested in only 12 patients, this surgical technique seems to be efficacious. It can be expeditiously performed, and the risks of postoperative complications related to the technique appear to be minimal. Larger series are indeed necessary before more definitive conclusions can be reached.
We thank our anesthesiologists, perfusionists, nurses, and operating department assistants for their assistance and cooperation. We dedicate our work to Dr Pierre Lebreton, anesthesiologist in our department, who died prematurely in August 1999.

\section{REFERENCES}

1. Caputo M, Wilde P, Angelini GD. Management of post-infarction ventricular septal defect. Br J Hosp Med 1995;54:562-6.

2. Raddford M, Johnson R, Daggett WJ, Fallon JT, Buckley MJ, Gold HK, et al. Ventricular septal rupture: a review of clinical and physiological features and an analysis of survival. Circulation 1981;64:545-53.

3. Muehrcke DD, Daggett WM. Current surgical approach to acute ventricular septal rupture. Adv Card Surg 1995;6:69-90.

4. Skehan JD, Carey C, Norrell MS, de Belder M, Balcon R, Mills PG. Patterns of coronary artery disease in post-infarction ventricular septal rupture. Br Heart J 1989;62:628-75.

5. Komeda M, Fremes SE, David TE. Surgical repair of postinfarction ventricular septal defect. Circulation 1990;82(Suppl):243-7.

6. Daggett WM, Guyton RA, Mundth ED, Buckley MJ, McEnany MT, Gold HK, et al. Surgery for post myocardial infarct ventricular septal defect. Ann Surg 1977;186:260-70.

7. Daggett WM. Postinfarction ventricular septal defect repair: retrospective thoughts and historical perspectives. Ann Thorac Surg 1990;50:1006-9.

8. Killen DA, Piehler JM, Borkon AM, Gorton ME, Reed WA. Early repair of postinfarction ventricular septal rupture. Ann Thorac Surg 1997;63:138-42.

9. Jones MT, Schofield PM, Dark JF, Moussalli H, Deiraniya AK, Lawson RAM, et al. Surgical repair of acquired ventricular septal defect: determinants of early and late outcome. J Thorac Cardiovasc Surg 1987;93:680-6.

10. Blanche C, Khan SS, Chaux A, Matloff JM. Postinfarction ventricular septal defect in the elderly: analysis and results. Ann Thorac Surg 1994;57:1244-7.

11. Davies LH, Dawkins KD, Skillington PD, Lewincton V, Monro $\mathrm{JL}$, Lamb RK, et al. Late functional results after surgical closure of acquired ventricular septal defect. J Thorac Cardiovasc Surg 1993;106:592-8.

12. Cooley DA, Belmonte BA, Zeis LB, Schnur S. Surgical repair of ruptured interventricular septum following acute myocardial infarction. Surgery 1957;41:930-7.

13. Daggett WM. Surgical technique for early repair of posterior ventricular septal rupture. J Thorac Cardiovasc Surg 1982;84:30612.

14. David TE, Dale L, Sun Z. Postinfarction ventricular septal rupture: repair by endocardial patch with infarct exclusion. J Thorac Cardiovasc Surg 1995;110:1315-22.

15. Berrizbeitia LD, McGrath LB. Repair of ventricular septal rupture through the right atrium. J Card Surg 1996;11:71-4.

16. Filgueira JL, Battistessa SA, Hestable H, Lorenzo A, Cassinelli M, Scola R. Delayed repair of an acquired posterior septal defect through a right atrial approach. Ann Thorac Surg 1986;42:208-9.

17. Chan BBK, Nolan SP, Kron IL. Transatrial approach to posterior postinfarct ventricular septal defect. Ann Thorac Surg 1996; 62:903-4.

18. Pezzella TA. Transatrial closure of postinfarction ventricular septal defect. Tex Heart Inst J 1992;19:297-9.

19. Pezzella TA. Postinfarct ventricular septal defect. [letter]. Ann Thorac Surg 1997;64:294-5. 
20. Engelman RM, Rousou JA, Schweiger M. Traumatic ventricular septal defect following closed-chest massage: a new approach to closure. Ann Thorac Surg 1984;38:529-32.

21. Rousou JA, Engelman RM, Breyer RH, Whittredge P, Snider R. Transatrial repair of postinfarction posterior ventricular septal defect. Ann Thorac Surg 1987;43:665-6.

22. Antunes MJ, Fernandes LE, Oliveira JM. Ventricular septal defects and arteriovenous fistulas, with and without valvular lesions, resulting from penetrating injury of the heart and aorta. $\mathbf{J}$ Thorac Cardiovasc Surg 1988;95:902-7.

23. Deville C, Fontan F, Chevalier J, Madonna F, Ebner A, Besse P. Surgery of post-infarction ventricular septal defect: risk factors for hospital death and long term results. Eur J Cardiothorac Surg 1991;5:167-75.

24. Blanche C, Khan SS, Chaux A, Matloff JM. Results of early repair of ventricular septal defect after an acute myocardial infarction. J Thorac Cardiovasc Surg 1992;104:961-5.

25. Cummings RG, Reimer KA, Califf R, Hackel D, Boswick J,
Lowe JE. Quantitative analysis of right and left ventricular infarction in the presence of postinfarction ventricular septal defect. Circulation 1988;77:33-42.

26. Da Silva JP, Cascudo MM, Baumgratz JF, Vila HA, Macruz R. Postinfarction ventricular septal defect: an efficacious technique for early surgical repair. J Thorac Cardiovasc Surg 1989;97:86-9.

27. Cooley DA. Repair of postinfarction ventricular septal defect. J Card Surg 1994;9:427-9.

28. Musumeci F, Shukla V, Mignosa C, Casali G, Ikram S. Early repair of postinfarction ventricular septal defect with gelatinresorcin-formol biological glue. Ann Thorac Surg 1996;62:486-8.

29. Calderon M, Ott DA. Surgical treatment of postinfarction rupture of the interventricular septum. Tex Heart Inst J 1991;18:282-5.

30. Koh Y, Kitanura N, Shuntoh K, Kawashima M, Tatebayashi T, Yamaguchi A. A successful transatrial repair of post-infarction ventricular septal defect. Nippon Kyobu Geka Gakkai Zasshi 1992;40:1733-7. 